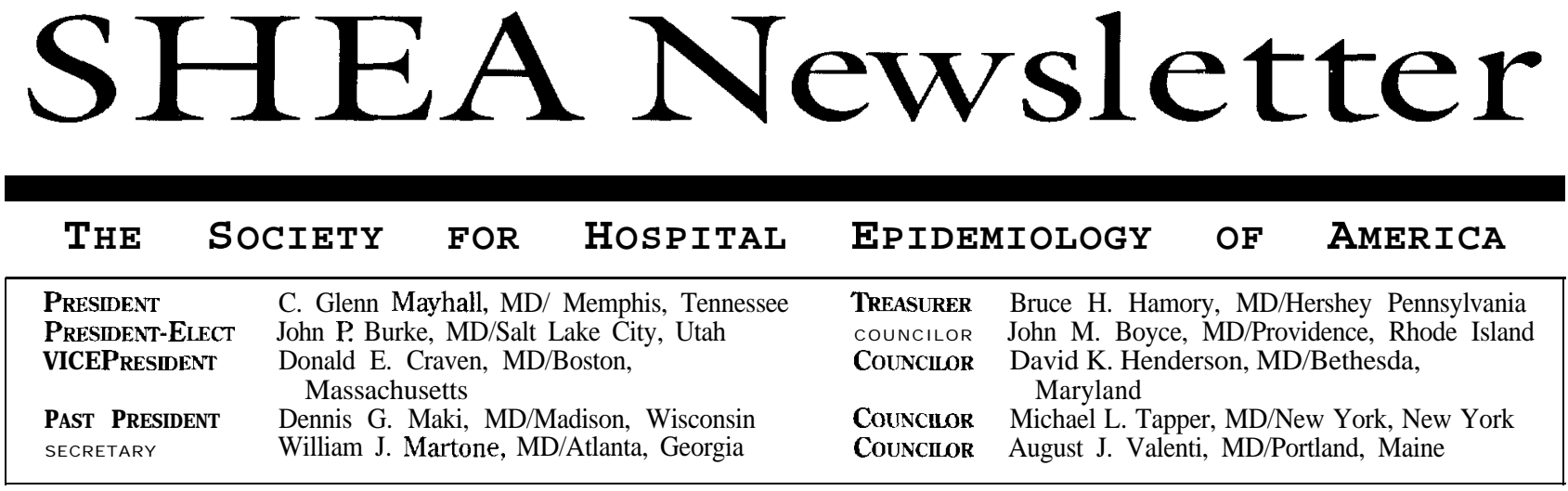

\title{
Announcement: SHEA's Second Annual Scientific Meeting
}

Get ready for some good

crab cakes and hospital epidemiology! Our second annual scientific meeting will be April 12-14, 1992, at the Omni Inner Harbor Hotel, Baltimore, Maryland. Reserve the date now.

The objectives of the conference are: to review methods for surveillance and prevention of adverse clinical outcomes; to update and review trends in nosocomial infections and pathogens, antimicrobial resistance, and human immunodeficiency virus (HIV) /acquired immunodeficiency syndrome (AIDS) prevention; to review progress in achieving National

Year 2000 objectives for

preventing nosocomial infection

in intensive care units and in

surgical patients; to present

information on surveillance and

prevention of occupational

infections and injuries; and to

identify areas for future research.

These broad objectives

should interest a large target audience, including not only hospital epidemiologists and infection control practitioners, but also quality improvement professionals, hospital administrators, surgeons, intensivists, and microbiologists.
The conference format will include symposia, scientific sessions, poster sessions, and industry exhibits. Original scientific contributions will be solicited actively. Abstract forms, registration forms, and housing forms will be included in the preliminary program.

The chair and co-chair for this exciting event are Drs. C. Glenn Mayhall and John P. Burke, respectively. For further information, please contact SHEA, 875 Kings Highway, Suite 200, West Deptford, NJ 08096. Telephone (609) 845-1636.

\section{Nominating Committee Chair Appointed for 1991}

Dale N. Gerding, MD, has been appointed chairperson of the Nominating Committee for 1991. The Committee will develop a slate of candidates for the election, to be held in the fall of 1991, for offices to be filled in
January 1992. The Committee will nominate candidates for vice president, treasurer, and two of the councilor offices. Members of SHEA who wish to suggest names to the Committee for consideration as candidates should submit the name(s) in writing to Dr. Gerding by June 1, 1991, at VA Medical Center, 111F, 1 Veterans' Drive, Minneapolis, MN 55417. His telephone number is (612) 725-2000 extension 4185 .

\section{Job Board-Centers for Disease Control}

There is a job opening for a medical officer in the Centers for Disease Control (CDC), Hospital Infections Program, AIDS Activity. The Activity is the Public Health Service (PHS) component responsible for the evaluation of the risk of transmission of human immunodeficiency virus (HIV) and HIV-related infection in healthcare settings and for the development, promulgation, and evaluation of guidelines to reduce this risk. Ongoing activities include multicenter observational studies in hospital emergency departments and operating and delivery rooms to assess the nature and frequency of occupational blood contact and efficacy of preventive measures; 